8

\title{
Developing IT-enabled virtual enterprises in construction
}

\author{
A.Grilo
}

PhD Candidate, University of Salford

Bridgewater Building, Salford, M5 4WT, UK, e-mail:

a.grilo@mail.telepac.pt

\section{L.T. Almeida}

Professor of Instituto Superior Técnico

Av. Rovisco Pais, 1000 Lisboa, Portugal

\author{
M.P. Betts \\ Professor of University of Salford \\ Bridgewater Building, Salford, M5 4WT, UK
}

\begin{abstract}
The achievement of IT-enabled virtual enterprises in construction is a fundamental step in order to raise productivity within construction projects, and therefore reduce costs, reduce lead times, and raise quality. Based on the patterns of successful IT-enabled virtual enterprises on manufacturing and service industries, this paper analyses what constraints and facilitates the initiation and development of electronic links within construction virtual enterprises.
\end{abstract}

Keywords

Construction, virtual enterprises, electronic links, networks

\section{INTRODUCTION}

The emerging of IT-enabled virtual enterprises in manufacturing and service industries has been a response to the global and increasing competition, and higher complexity of products/services. The complex management of these networks of firms is supported by Information Technology, which facilitate and stimulate inter-organisational communications. Competitive advantage of firms is increasingly determined by the effective management of the interdependencies within the virtual enterprise, and 
therefore the strategic role of IT is shifting from internal operations to inter-organisational functions.

Construction virtual enterprises existed well before emerging in manufacturing/service industries. Regardless of the ineffective management of the interdependencies and of poor information flows, electronic links are absent of construction virtual enterprises. Main contractors do not seem to embrace the potential of IT in order to exchange information with designers, manufacturers, material suppliers, subcontractors, etc.

This paper aims at contributing to a better understanding of the lack of electronic links within construction virtual enterprise. A model is presented which allows a comparison between successful IT-enabled virtual enterprises in manufacturing/service industries and construction cases.

\section{IT-ENABLED VIRTUAL ENTERPRISES}

One of the most relevant and smooth innovations in manufacturing firms has been the emergence of the concept of virtual enterprises. Current goods manufacturing see over $60 \%$ of the value of the product added not by the manufacturer who sells the final product, but by other manufacturers, usually designated as suppliers. The outsourcing of value adding activities to specialist firms, which manufacture at better quality and lower costs components and/or sub-assemblies, has shift responsibility from manufacturing departments and production planning departments to the purchasing departments and to suppliers. Purchasing has become supply management. Examples can be found in automotive industry (Lamming, 1993), in clothing, book publishing, electronics, etc. (Miles and Snow, 1992).

There is no unique form or definition for virtual enterprises, but in a general way it is considered as a network of organisations that exists for the development and manufacture of one or few products/services. These are usually characterised by having intermediate forms between markets (competitive arm's-length supply) and vertical integration. Virtual enterprises may be organised around a core firm, usually a large firm, which co-ordinate the network of firms, usually SMEs, or may be self-organising between firms, with no enduring leader (Harrison, 1994).

Hence, in order to obtain sustainable competitive advantage, companies have to look beyond internal boundaries, as competitive advantage lie partly within a given organisation and partly in the larger network of firms around it (Venkatraman, 1991). Their greatest challenge is to know how to manage effectively the interdependencies and relationships of the network, and efficiently the internal business processes. Firms must regard logistics processes (physical and information flows) as important as production processes. A major facilitator to the coordinating function is Information Technology (IT), by linking electronically through EDI, interactive on-line databases, Internet, video-conferencing, E-mail, etc. the organisations belonging to the virtual enterprise. IT can facilitate and stimulate inter-organisation communication, by providing more adequate, timely, and accurate information. The benefits from the use of IT for the coordination of the virtual enterprise vary accordingly to the technology but in a generic way, they can reduce costs, shorten lead times, and raises quality (Venkatraman, 1991). 


\section{THE CONSTRUCTION PROJECT VIRTUAL ENTERPRISE}

Although new to the manufacturing firms, the virtual enterprise concept has long been used in the construction industry. Indeed, temporary networks of "co-operating" organisations have existed for a long time in the construction industry, usually denominated by temporary multiple organisations (Cherns and Bryant, 1983). In a traditional and simplistic way, construction projects are split into the design and construction phases. The architect is the project leader, developing a design and design management responsibility and devolving a role for specialist design and management functions to engineers, surveyors and the like. On the construction phase a main contractor is responsible for the completion of the entire project and procures the services of specialised firms. These specialised firms are subcontractors who carry out work on-site, and suppliers who manufacture products off-site and deliver them as needed. In a generic way, for each project, a virtual enterprise is assembled in order to build the product.

Construction managers and researchers stress that the construction organisation is the main responsible factor for the problems of low productivity and innovation of the industry (Hillebrant and Cannon, 1990; Atkin and Pothecary, 1994). Current procurement and organisational developments in the sector are increasingly focusing on more effective management of the virtual enterprise through developments such as design and build, multidisciplinary design and project management, etc. (Latham, 1994). But although some progress has been achieved, there has not been significant improvements.

Looking from the example of manufacturing and service virtual enterprises, we must conclude that the problem is not grounded on the construction organisational structure but on the way construction virtual enterprises are managed, which is supported by inefficient information flows. Indeed, a good project management must pay as much attention to the production as to the overall information flow. Increases of $15 \%$ to $20 \%$ in the performance of projects (cost, quality, speed, customer satisfaction) may be accomplish if the information flow within the network of relationships in the virtual enterprise are carefully addressed and improved (Latham, 1994). The geographical distance between headquarters of the companies and the construction sites, which have a limited existence in time and space, makes it difficult to have on-line information on planning of activities and resources and their control. Moreover, little attention has been given to the establishment of effective communication and logistics processes involving designers, contractors, subcontractors and material suppliers.

A contrasting difference between manufacturing/service virtual enterprises and construction virtual enterprises is that the former are enabled and supported by IT. Indeed, a benchmarking study to the largest contractors in the UK revealed that contractors did not have any type of electronic links with their subcontractors, material suppliers, manufacturers, designers, etc. (Betts et al, 1995). Another study has shown that although there are electronic links between building merchants and their suppliers (manufacturers and material suppliers) there was no electronic links whatsoever with contractors (Baldwin, 1995). In the UK, despite some recent national initiatives to develop electronic trading between contractors and their suppliers, the results have been widely disappointing. Again, common explanations advocate that the industrial structure and organisation of construction does not encourage electronic links: its industry fragmentation; fragmented clients; unique nature of each project; and lack of IT standards are often blamed (see e.g. Construct IT - Bridging the Gap, HMSO, 1995; or Baldwin et al, 1995). 


\section{CONSTRAINTS AND FACILITATORS OF IT-ENABLED VIRTUAL ENTERPRISES}

In our perspective, more coherent and robust theoretical explanation is required in order to better understand the lack of electronic links on construction virtual enterprises, with focus on the large main contractors-suppliers interactions, but also to pave the way forward. Thus, it is important to analyse what constraints and facilitates the initiation and development of ITenabled virtual enterprises, and how electronic links influence the organisation of virtual enterprises. The approach used is based on the development of a generic model and the construction case is made by comparison with successful IT-enabled virtual enterprises.

The complexity of the inter-relationship and interdependencies of firms belonging to a virtual enterprise and the definition of its boundaries is a complex research issue. The network of firms which support a virtual enterprise may be compound by hundreds of firms, and even thousands if we consider the next level of suppliers (the suppliers of main suppliers). This complexity means that the boundaries of research will need to be defined in such a way as to allow to tackle the complexity. In this work we tackled the problem by defining a series of dyadic interactions (one-to-one relations) between the firms, essentially between a hub firm (e.g. a buying/core firm like a retailer, automotive assembler, main contractor, etc.) and the suppliers. These dyadic interactions are embedded within a web of relationships which may shape their patterns. Finally, this web of relationships is embedded on the environmental context (e.g. industry culture, technological trends, etc.). The model presented here relates only to the dyadic level, and is based on literature research. Empirical validation is currently being held.

The model defines that there are four main conditioning factors that constraint and enable the initiation and development of electronic links on dyadic interactions on virtual enterprises, as depicted in Figure 1.

\section{Governance structure}

This factor addresses the issues related with the co-ordination mechanism of the dyadic interaction. It is related with the power dependence of firms, i.e. if one firm is dominant over the other or if the power is balanced. It is also about the relationships. These can be seen as lying in a continuum. At one extreme, relationships are competitive, free-market, mostly distant or adversarial, with low levels of trust, and usually short-term. On the other extreme, relationships are co-operative, collaborative, there is mutual trust, and a commitment to the long-term interaction.

\section{Information exchange}

Refers to the information that is transferred between the hub firm and supplier and vice-versa. It is related with the type of information that is shared, which may be operational information such as enquiries, delivery times, project planning, cash management, etc.; tactical information such as joint process improvement, joint targeting of objectives, sales forecasts, etc.; and strategic information e.g. new businesses new products, strategic partnering, etc.. Another important issue is the information quality i.e. related with the information adequacy, timeliness, accuracy, and transparency. 


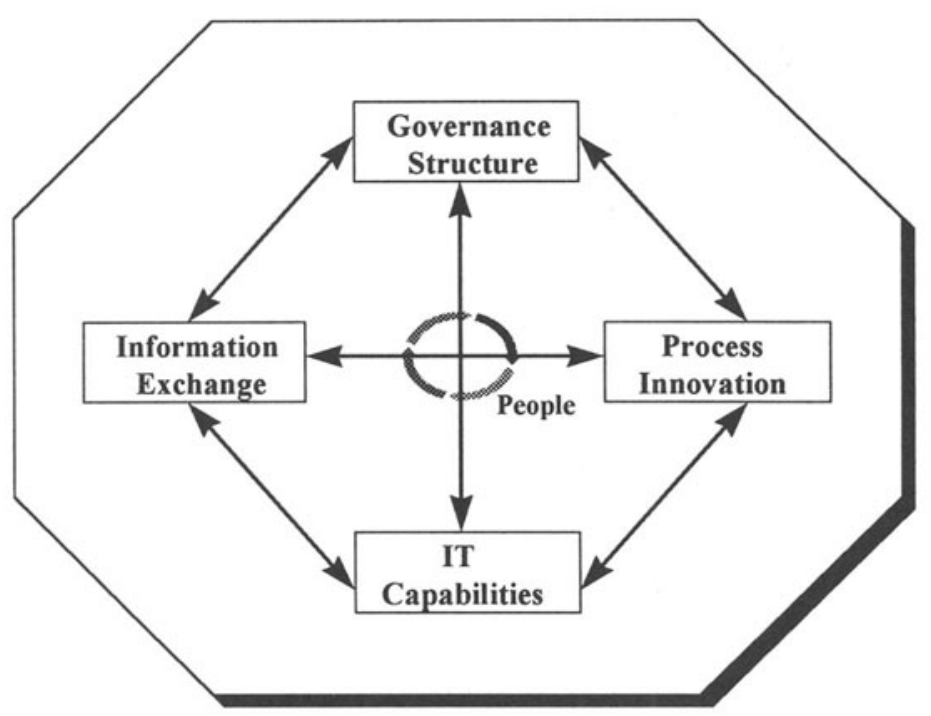

Figure 1 Conditioning factors for the development of an IT-enabled dyadic interaction

\section{Process innovation}

It refers to the changes which occur on internal business processes and related with the deployment of electronic links. The scope of the changes in the processes is an important issue and these can vary from incremental changes, simple automation or elimination of tasks, to radical re-engineering of logistics and purchasing functions, etc. Also, the benefits that firms obtain from process changes is an important issue, and these can vary from operational benefits like cost reduction, reduced life cycle, to strategic benefits such as more flexibility and responsiveness, more and better trade, etc.

\section{Technology}

It refers to the technology utilised for the electronic exchange of information/data, i.e. EDI, Email, interactive on-line databases, groupware, Internet, etc. It also addresses the internal IT capabilities of firms.

In Table 1 a comparison is made between the patterns of the conditioning factors of successful IT-enabled dyadic interactions and of construction dyadic interactions. 
Table 1 Patterns of the conditioning factors

\begin{tabular}{|c|c|}
\hline Successful IT-enabled dyadic interactions & Construction dyadic interactions \\
\hline Governance & Structure \\
\hline $\begin{array}{l}\text { Hub firm has buying power over supplier } \\
\text { - More co-operative, collaborative and mutually } \\
\text { trustful relationships. Commitment to long- } \\
\text { term relations based on formal agreements. }\end{array}$ & $\begin{array}{l}\text { - Main contractor has little buying power over } \\
\text { suppliers. } \\
\text { - There is little co-operation and collaboration } \\
\text { and relations are usually adversarial. Firms } \\
\text { are usually committed only to the project } \\
\text { duration. }\end{array}$ \\
\hline Information & Exchange \\
\hline $\begin{array}{l}\text { Hub and suppliers tend to share more than } \\
\text { operational information, often tactical and } \\
\text { sometimes strategic. } \\
\text { - Information is more accurate, adequate and } \\
\text { timely. There is also more } \\
\text { openness/transparency. }\end{array}$ & $\begin{array}{l}\text { - Contractor and suppliers share the minimal } \\
\text { information possible. Restricted to the project } \\
\text { operational information } \\
\text { - Project information is usually not available } \\
\text { when is needed, it is often not very accurate, } \\
\text { and it is definitely not transparent. }\end{array}$ \\
\hline Process & Innovation \\
\hline $\begin{array}{l}\text { - There is usually incremental changes in } \\
\text { internal logistics and purchasing processes. } \\
\text { Some radical changes on processes happen. } \\
\text { - Hub firm seeks essentially operational } \\
\text { benefits, which can be high even with } \\
\text { incremental changes. Suppliers achieve } \\
\text { essentially strategic benefits. }\end{array}$ & $\begin{array}{l}\text { - Contractors do not see purchasing and } \\
\text { logistics as core processes. There is a lack of } \\
\text { believe that improvements on these processes } \\
\text { may bring benefits. } \\
\text { - General believe that benefits may only be } \\
\text { achieved if radical changes are made to the } \\
\text { construction process }\end{array}$ \\
\hline \multicolumn{2}{|c|}{ Technology } \\
\hline $\begin{array}{l}\text { Open technology and simple, widely available } \\
\text { and mature technology like EDI, E-mail and } \\
\text { interactive on-line databases are the most } \\
\text { common. } \\
\text { - Hub firms have usually considerable internal } \\
\text { IT capabilities. Suppliers have some IT } \\
\text { capabilities and are often helped by the hub } \\
\text { firm }\end{array}$ & $\begin{array}{l}\text { Contractor's IT capabilities are usually good } \\
\text { but lack any expertise on electronic } \\
\text { communications. Suppliers have usually very } \\
\text { low IT capabilities. } \\
\text { - There is not many construction specific IT } \\
\text { standards, but technology from other } \\
\text { industries may be easily adapted. }\end{array}$ \\
\hline
\end{tabular}

The patterns of successful IT-enabled dyadic interactions are rarely in place before the full deployment of electronic links, and it is obscure which were the initial patterns, the causes and the effects. However, a sharp difference can be found between what is happening in construction dyadic interactions and dyadic interactions of successful IT-enabled virtual enterprises. We believe that IT-enabled virtual enterprises emerge more easily where the necessary effect upon the patterns of each conditioning factor will be lower in order to achieve the "successful pattern". In a generic way, dyadic interactions on construction virtual enterprises require large "investments" in order to achieve the pattern of successful IT-enabled dyadic. It is this gap between the required pattern and the real pattern of conditioning factors that is hindering the development of construction IT-enabled virtual enterprises (Grilo et al, 1996).

Moreover, conditioning factors interplay with each other in a complex way, creating selfreinforcing systems that can either facilitate or hinder the development of IT-enabled dyadic in order to exemplify. 
- Collaboration, mutual trust, and long term commitment usually lead firms to share more tactical and strategic information, and also on a more open way. If firms share information about internal processes they can more easily envisage better ways of working together and achieve radical and dramatic changes with electronic links. A good example is given by the automotive assemblers that have been working with some major suppliers in order obtain lean production and supply (Lamming, 1993). In construction virtual enterprises, adversarial and short-term relationships lead to basic project operational information sharing, which is usually of low quality and non-transparent, and not allowing firms to envisage efficient ways to deploy electronic links in order to improve business processes.

- The deployment of complex and/or close IT systems for electronic links, such as proprietary groupware, graphical images, and advanced or proprietary EDI systems usually implies a high level of collaboration between firms, which will be difficult to achieve if companies have adversarial attitudes. Moreover, companies will not be willing to invest capital, time and resources if they have not some sort of guarantee that they will be trading on a longterm basis. On the other hand, open and widely available systems like those from the Internet do not usually require that firms have long-term, collaborative relationships.

- Often, supplier firms make process changes and deploy IT systems because they are coerced by hub firms, which have usually buying power over them. They often are also coerced to share more information than they were initially willing to. In construction virtual enterprises, main contractors do not have enduring buying power over suppliers, as it last only to the project duration. Thus, they can not coerce their suppliers in order to deploy IT systems or improve business processes.

Finally, it is important to remark that although the pattern of the conditioning factors of dyadic interactions may be greatly influenced by the web of relationships involved on the virtual enterprise, which are usually influenced by environmental characteristics (like industry culture, technological trends, etc.), these patterns are basically a matter of individual choice of firms. Against industries' culture and way of working, pioneering firms in automotive, retailing, clothing, etc. industries had to develop IT-enabled dyadic interactions by investing in collaborative relationships, by sharing tactical and strategic information with their suppliers, by acknowledging that improvements in logistic and purchasing functions could contribute to the overall business performance, and developing their own IT systems with (by then) immature technology.

Unarguably that current characteristics of construction virtual enterprises do not facilitate the emerging of enabling patterns on conditioning factors. However, it is basically a matter of choice of construction firms. Some positive evidence has been emerging recently. The partnering concept has been developing in the US, Australia and UK, although on a very restrict way (Bennett and Jayes, 1995). In Sweden, the large contractor Skanska on a reengineering effort has identified the logistic and purchasing processes as the ones with greatest potential for improvement (Betts, 1996). They have established long-term formal agreements with major suppliers and are developing with them electronic links. 


\section{CONCLUSIONS}

This paper addressed the problem of the lack of electronic links within construction virtual enterprises. It analysed what constraints and facilitates the initiation and development of ITenabled enterprises, and why construction firms have not electronic links. In a generic way, it is concluded that the electronic linking of construction virtual enterprises requires that main contractors and suppliers develop more collaborative, trustful and long-term committed relationships. Construction firms will need to share more than basic project operational information, with more quality and transparency. Another crucial factor is the acknowledgement by construction firms of the importance and potential benefits of logistic and purchasing processes to the overall construction process. Finally, construction firms must develop IT capabilities as far as electronic communications are concerned. Following examples on other industries, collaborative and co-operative efforts between main contractors and suppliers on technology development are crucial.

\section{REFERENCES}

Atkin, B. and Pothecary, E. (1994), Building Futures; University of Reading, Dept. of Construction Management and Engineering

Baldwin, A., Thorpe, A, and Carter, C. (1995), Data Exchange in Construction: EDI, MFE or IE? in Developments in Computational Techniques For Civil Engineering, pp 11-15, B.H.V Topping, Civil-Comp Press, Edinburgh, UK

Bennett, J. and Jayes, S. (1995), Trusting the Team: Best Practice Guide to Partnering in Construction, CSSC, University of Reading

Betts, M., Atkin, B. and Clark, A. (1995), Best Practice Report: Supplier Management; Construct IT - Centre of Excellence, HMSO

Cherns, A. and Bryant, D. (1983), Studying the Client's Role in Construction Management; Construction Management and Economics, 2 , pp117

Grilo, A., Betts, M. and Mateus, M. (1996), Electronic Interaction in Construction: Why Is It Not a Reality?; in CIB Proceedings of the Construction on The Information Highway, Bled, Slovenia

Harrison, B. (1994), Lean and Mean: The Changing Landscape of Corporate Power in the Age of Flexibility; BasicBooks, New York

Hillebrant, P.M and Cannon, J. (1990), The Management of Construction Firms; Macmillian

Lamming, R. (1993), Beyond Partnership: Strategies for Innovation and Lean Supply; Prentice Hall

Latham, Sir M. (1994); Constructing the Team; HMSO

Miles, R.E. and Snow, C. (1992), Causes of Failure in Network Organizations; California Management Review, Summer, pp53-72

Venkatraman, N. (1991); IT-induced Business Reconfiguration, in The Corporation of the 1990s: Information Technology and Organizational Transformation, Oxford University Press 